\title{
Estudo da Síndrome de Burnout em Estudantes de Psicologia
}

\author{
Study of Occupational Burnout in Psychology Graduate Students \\ Estudio del Sindrome de Burnout en Estudiantes de Psicologia
}

\author{
Fernanda Luzia Lopes \\ Universidade São Francisco - Itatiba-SP \\ Gisele Soares Guimarães \\ Universidade São Francisco - Itatiba-SP
}

\begin{abstract}
Resumo
Este estudo teve por objetivo averiguar a incidência de casos da síndrome de Burnout em estudantes universitários do curso de Psicologia, bem como investigar sua associação às variáveis acadêmicas e sociodemográficas. $\mathrm{O}$ estudo foi realizado com uma amostra de 111 estudantes de uma instituição privada do interior de São Paulo. Como instrumento desta pesquisa foi utilizado o Maslach Burnout Inventory-Student Survey (MBI-SS) e um questionário para identificar as variáveis acadêmicas e sociodemográficas. O resultado do estudo identificou que o sentimento de descrença foi maior nos estudantes que já cogitaram abandonar o curso; que não possuem/concluíram outro curso superior; do sexo feminino; e/ou são relativamente jovens. O sentimento de exaustão emocional foi maior nos estudantes na faixa etária de 27 a 30 anos. Já em relação à eficácia profissional, apenas estudantes que possuíam outro curso superior apresentaram maiores escores nessa dimensão. $O$ resultado da pesquisa não mostrou a prevalência da síndrome na amostra pesquisada, porém, os resultados encontrados ressaltam a importância de ações interventivas que minimizem fatores estressores que possam contribuir para o desencadeamento da síndrome de Burnout nesses futuros profissionais.
\end{abstract}

Palavras-chave: universitários; estresse; saúde; esgotamento profissional; síndrome de Burnout.

Abstract

This study aims to investigate the prevalence of Occupational Burnout (Burnout syndrome in Portuguese) in Psychology graduate students, as well as to investigate their association with academic and sociodemographic variables. The study was carried out with a sample of 111 students from a private institution in the interior of São Paulo. For this research was applied the Maslach Burnout Inventory-Student Survey (MBI-SS) and a questionnaire to identify the academic and sociodemographic variables. The results have shown that the feeling of disbelief was greater in students who already considered dropping out course; do not have completed another university degree; female gender; and are relatively young. The feeling of emotional exhaustion was greater in students in the age group of 27 to 30 years. Regarding the professional effectiveness, only students who had another university degree presented higher scores in this dimension. However, the results of this study did not show the prevalence of Occupational Burnout in the sample studied, but, the findings highlight the importance of intervention actions in order to minimize stressors that may contribute to the onset of Occupational Burnout/Burnout Syndrome in these future professionals.

Keywords: graduate students; stress; health; professional exhaustion; occupational Burnout.

Resumen

Este estudio tuvo como objetivo investigar la incidencia de casos del síndrome de Burnout en estudiantes universitarios del curso de psicología, bien como investigar su asociación a las variables académicas y sociodemográficas. El estudio fue realizado con una muestra de 111 estudiantes de una institución privada del interior de São Paulo. Como instrumento de esta investigación fue utilizado el Maslach Burnout Inventory-Student Survey (MBI-SS) y un cuestionário para identificar las variables académicas y sociodemográficas. El resultado del estudio identificó que el sentimiento de incredulidad fue mayor en los estudiantes que ya cogitaron abandonar el curso; que no poseen/ concluyeron otro curso superior; del sexo femenino; y/o son relativamente jóvenes. El sentimiento de cansancio emocional fue mayor en los estudiantes en la franja de edad de 27 a 30 años. Ya en relación a la eficacia profesional, sólo estudiantes que poseían otro curso superior presentaron mayores puntuaciones en esa dimensión. El resultado da la investigación no mostró la prevalencia del síndrome en la muestra investigada, sin embargo, los resultados encontrados destacan la importancia de acciones interventivas que reduzcan factores de estrés que puedan contribuir para el desencadenamiento del síndrome de Burnout en esos futuros profesionales.

Palabras-clave: universitários; estrés; salud; agotamiento profesional; síndrome de Burnout. 
A síndrome de Burnout (SB) vem sendo, cada vez mais, fonte de investigação e de interesse dos pesquisadores. No início, as pesquisas eram voltadas aos trabalhadores da área de assistência social, educadores e profissionais de enfermagem. Entretanto, nos últimos anos, outras profissões, especialmente àquelas relacionadas à saúde, vêm sendo objeto de estudo, dados os potenciais incidentes da síndrome nessas categorias (Borges \& Carlotto, 2004). Os estudos sobre Burnout começaram a aumentar em meados da década de 70, por meio de uma pesquisa realizada pelo médico psiquiatra Freudenberguer, em que foram identificados, em um grupo de jovens voluntários e idealistas que ajudavam usuários de substâncias psicoativas, sentimentos como incompreensão, falta de motivação e desumanização para com os pacientes, diante da dificuldade de aderência ao tratamento (Ferreira, 2012).

Nessa época, o conceito de Burnout foi empregado para falar do desgaste físico e emocional que os profissionais da área da saúde apresentavam, entendendo que a síndrome está ligada às questões do trabalho (Pereira, 2002). No decorrer dos anos, esse conceito passou por ampliações como forma de melhorar a compreensão de seus conceitos e dos fatores a ele relacionados, hoje se entende que a síndrome, além de estar ligada a situação do trabalho, também é compreendida pelo contexto de vida na qual o trabalhador encontra-se inserido, além de envolver aspectos das relações interpessoais (Ferreira, 2012).

Atualmente a síndrome de Burnout é reconhecida pelo Ministério da Saúde (1999) como "transtorno mental e do comportamento relacionado com o trabalho e compõe a lista de doenças relacionadas ao trabalho", neste ponto, de acordo com Jacques, Borges, e Cassiolato (2010), o Brasil encontra-se relativamente à frente de outros países que ainda não caracterizam a síndrome como uma doença do trabalho, mas apenas como um acidente de trabalho. Os autores citam como exemplo uma lei trabalhista da Espanha. Neste país, o profissional que lida com pessoas com necessidades especiais, por direito, podem receber um valor adicional no salário por periculosidade, já que se entende que tal condição de trabalho pode ser favorável ao surgimento da síndrome.

O Burnout é visto como um processo de estresse crônico no ambiente de trabalho e pode ser caracterizado pelo sentimento de esgotamento total de energia (Campos, Carlotto, \& Marôco, 2013). Segundo Ferreira (2012, p.22), "Esse termo é definido, segundo um jargão inglês, como aquilo que deixou de funcionar por absoluta falta de energia, decorrente de um processo de cronificação do estresse no trabalho". Pereira (2002) afirma que a síndrome não se caracteriza somente pelo estresse, mas engloba outros fatores relacionados à atividade laboral. Os autores Carlotto, Nakamura, e Câmara (2006) definem o Burnout como um conjunto de três fatores psicossociais, são eles: exaustão emocional, despersonalização e baixa realização profissional.

De acordo com Maroco e Tecedeiro (2009), a exaustão emocional pode ser entendida como desgaste emocional, psicológico e moral do indivíduo. Telles e Pimenta (2009) corroboram essa definição e acrescentam que além do desgaste, ocorre também a falta de recursos para lidar com o cotidiano profissional, tudo isso faz com que emerja sentimentos de tensão e esgotamento. Já a despersonalização, de acordo com Telles e Pimenta (2009), está relacionada aos sentimentos de frieza, que surgem ao entrar em contato com a pessoa que o profissional precisa lidar, o profissional começa a ser áspero ao responder as pessoas, atendendo com indiferença os pacientes que necessitam do seu serviço (Carlotto et al., 2006). Autores (Carlotto, Câmara, Otto, \& Kauffmann, 2009; Maia, Maciel, Vasconcelos, Vasconcelos, \& Filho, 2012), conceituam "descrença” para se referir ao sentimento de cinismo e distanciamento vivido por estudantes.

A baixa realização profissional, por sua vez, está relacionada à insatisfação profissional (Borges \& Carlotto, 2004) e ao sentimento de incompetência em relação ao trabalho realizado com pessoas (Carlotto \& Câmara, 2006), ainda, o trabalhador acaba fazendo uma avaliação negativa acerca de si, além de interagir cada vez menos com as pessoas 
que fazem parte da sua rede profissional. Todos esses fatores são decorrentes de um desgaste emocional, dada à exposição contínua a agentes estressores, sendo visto como um estresse ocupacional; e são diversas as formas como a síndrome pode se manifestar, em alguns casos é possível observar a falta de produtividade, absenteísmo, consumo de substâncias psicoativas, depressão entre outros (Maroco \& Tecedeiro, 2009).

No que se refere aos estudantes, os critérios para se avaliar o Burnout são também constituídos por três dimensões: "exaustão emocional, caracterizada pelo sentimento de estar exausto em virtude das exigências do estudo; descrença, entendida como o desenvolvimento de uma atitude cínica e distanciada com relação ao estudo; e ineficácia profissional, caracterizada pela percepção de estarem sendo incompetentes como estudantes" (Borges \& Carlotto, 2004, p.47).

O Burnout apresenta alguns sintomas físicos, psíquicos, comportamentais e defensivos. De acordo com Pereira (2002), entre os sintomas físicos podem ser observados cefaleia, distúrbios do sono, dores musculares, cansaço, problemas gastrointestinais, transtornos cardiovasculares, distúrbios da menstruação entre outros. Como sintomas psíquicos a autora engloba falta de atenção e concentração, labilidade emocional, baixa autoestima, impaciência, alteração de memória, pensamento lentificado, depressão, desânimo etc. Em relação aos sintomas comportamentais, Araujo (2008) descreve comportamento suicida, negligência, irritabilidade, agressividade, dificuldade para relaxar, dificuldade para aceitar mudanças, falta de iniciativas e consumo de substâncias. Entre os sintomas defensivos, o absenteísmo, o isolamento, a vontade de abandonar o trabalho, a ausência de interesse pelo labor, demonstração de ironia e cinismo.

Esses sintomas podem ser confundidos com sintomas apresentados no estresse ocupacional, os autores Abreu, Stoll, Ramos, Baumgardt, e Kristensen (2002) falam, porém, que há uma diferenciação entre o Burnout e o estresse ocupacional. Embora ambos se relacionem com o labor, o primeiro resulta de diversas tentativas de lidar com o estresse, de forma que o estresse ocupacional é uma síndrome pontual, que quando não é devidamente tratada pode desencadear o Burnout, sendo um diferencial neste caso a aparição do fator despersonalização. Os mesmos autores salientam que há uma dessensibilização voltada para as pessoas que se relacionam diretamente com o profissional, estes podem incluir desde usuários de um sistema até a própria organização.

Os profissionais da saúde acabam sendo as grandes vítimas do Burnout, já que seu trabalho está diretamente relacionado com o cuidar do outro, além disso, o trabalhador acaba enfrentando diversos estressores ocupacionais como, por exemplo, longa jornada de trabalho, contato frequente com o sofrimento, dor e às vezes óbito, falta de reconhecimento, baixos salários etc.; nesse sentido, a área da saúde acaba exigindo um grande controle emocional do profissional (Kovaleski \& Bressan, 2012). Ferreira (2012) corrobora e acrescenta que dentro do ambiente hospitalar existe ainda uma divisão de trabalho que cinde os profissionais em diversas categorias o que cria diversos níveis hierárquicos e contribui para o surgimento de inúmeras regras e procedimentos, além de uma maneira formal de comunicação, contribuindo para o surgimento tanto de conflitos relacionados à execução de trabalho, quanto conflitos relacionados a procedimentos administrativos.

Um estudo realizado por França e Ferrari (2012) com 141 profissionais de enfermagem de um hospital de urgência e emergência de uma cidade do Mato Grosso, revelou por meio do inventário Burnout de Malash, que 9,58\% dos profissionais apresentaram a $\mathrm{SB}$, sendo que desse número, $53,84 \%$ são enfermeiros e $46,16 \%$ são técnicos ou auxiliares de enfermagem. Os autores afirmam que os enfermeiros, apesar de possuírem menor envolvimento com o paciente são submetidos a outros estressores, por exemplo: são eles os responsáveis pelo andamento do serviço e pela supervisão da equipe sendo constantemente cobrados tanto pela administração, quanto pelos médicos, técnicos e até mesmo familiares, o que 
favorece o aumento do estresse no ambiente e contribui para o surgimento da síndrome.

De acordo com Pereira (2002), o nível de responsabilidade no ambiente hospitalar tem sido um dos grandes fatores apontados como propiciador da síndrome, já que o profissional é apontado muitas vezes como responsável pela vida do outro - qualquer erro pode ser fatal - daí advém às cobranças tanto do próprio profissional, quanto da equipe, dos pacientes e dos familiares; qualquer erro pode trazer também consequências irreparáveis na vida do trabalhador.

Resultados semelhantes ao estudo de França e Ferrari (2012) foram encontrados anteriormente em um estudo realizado em enfermeiros de um hospital universitário de alta complexidade, o estudo contou com uma amostra de 149 enfermeiros e identificou a prevalência da síndrome em 10,22\% dos profissionais (Lorenz, Benatti, \& Sabino, 2010). De acordo com os autores, no resultado da pesquisa $49,2 \%$ dos enfermeiros relataram apresentar problemas de saúde nos últimos seis meses, reforçando desta forma que os estressores psicossociais podem desencadear doenças tanto quanto os micro-organismos; os autores afirmam também que a tensão vivida no ambiente de trabalho, as cobranças e a longa jornada de trabalho são fatores que contribuem para o surgimento desses estressores psicossociais.

Além dos profissionais de enfermagem, outros profissionais da área da saúde também são passíveis de desenvolver a síndrome de Burnout, entre eles podemos citar os médicos e psicólogos (Kovaleski \& Bressan, 2012). Os médicos por vezes, apresentam sintomas de grande sofrimento psíquico, oriundos das más condições de trabalho (falta de infraestrutura, superlotação, falta de equipamentos, etc.), falta de reconhecimento, carga excessiva de trabalho, baixos salários, entre outros (Selig, Geluda, Junqueira, Brito, \& Trajaman, 2012). Os autores salientam que muitas expectativas são criadas tanto pela população quanto pelo próprio profissional, são esperados que esses possuam empatia, sejam solidários e sensíveis e possam dar um acolhimento à população, à medida que as más condições vão sendo frequentes, os profissionais vão se frustrando, tendo o nível de estresse elevado, o que contribui para o desenvolvimento do Burnout.

Conforme já citado, os profissionais da saúde estão expostos a situações de grande tensão e pressão, tendo que lidar o tempo todo com a frustração, além disso, exercem uma profissão que exige responsabilidade sobre a vida do outro e desta forma, acabam sendo as maiores vítimas do Burnout (Abreu et al., 2002). Nessa perspectiva, o profissional da Psicologia convive com diversos fatores estressantes no dia a dia de sua profissão. Inicialmente o psicólogo recém-formado pode sair da graduação sem uma devida formação, com isso acabam fantasiando que são seres onipotentes e que podem resolver todos os problemas dos pacientes (Carlotto \& Nakamura, 2006). Para as autoras, ao entrar em contato com a realidade profissional esses recém-formados precisam lidar com inúmeros problemas, que vão desde pouca estrutura (relacionadas às instituições e serviços públicos), até o despreparo para atender demandas especificas, como por exemplo, lidar com um paciente acometido de um transtorno mais severo.

Biehl (2009) ressalta que muitas vezes o psicólogo precisa desempenhar suas atividades em diferentes locais, por exemplo, dividem sua rotina semanal entre atendimentos clínicos e pesquisa, consultoria e atividades dentro de organizações, docência e atuação em hospitais, entre outros, o que pode acabar acarretando uma sobrecarga de trabalho e estressores relacionados ao ambiente ocupacional. Dentro dessa perspectiva, uma pesquisa realizada pela mesma autora, com uma amostra de 915 psicólogos, mostrou que os profissionais que exerciam mais de uma atividade, ou exerciam atividades estressantes naquele momento, apresentaram alta exaustão emocional, alta despersonalização e baixa realização profissional, o que indica que os fatores relacionados ao trabalho estavam relacionados com o Burnout. Neste estudo a pesquisadora utilizou, além de um questionário sociodemográfico, o Inventário de Burnout em Psicólogos (IPB), um instrumento específico para 
profissionais de Psicologia que examina o mesmo alicerce do MBI, porém, utiliza uma linguagem própria para o trabalho do psicólogo.

Segundo Abreu et al. (2002), os psicólogos que trabalham no campo da saúde mental possuem um agravante de estressores pois, de acordo com os autores, pode haver a criação de um laço afetivo com os pacientes, nesse caso o profissional precisa manter essa relação quando essa se faz terapêutica, além disso, o profissional desenvolve um envolvimento maior com o paciente principalmente quando este encontrase no ambiente clínico. Ademais, outros fatores são relacionados às expectativas que são criadas acerca de seu trabalho, além de falta de gratificação e identificação com a problemática do paciente.

More e Cooper (citado por Abreu et al., 2002) sugerem que os psicólogos que lidam com a saúde mental podem criar expectativas a respeito da melhora do paciente, algumas vezes idealizam que seu trabalho trará grandes mudanças na vida do paciente. Porém, podem se deparar com um quadro de pequena melhora, ou ainda esperam que o processo de melhora seja rápido, quando na verdade a mudança se caracteriza por um processo longo e gradativo.

Biehl (2009) corrobora tal posicionamento e salienta que o ambiente de trabalho pode ser um fator estressor. De acordo com a autora, quando o psicólogo atua em instituições privadas (tendo a remuneração por meio de convênios ou agências de saúde), além de lidar com as demandas do paciente, o psicólogo precisa lidar com as burocracias institucionais, esperas longas pelo reembolso e outras limitações externas. A autora acrescenta que o profissional pode se deparar com uma situação em que as exigências superam as recompensas trazidas pelo labor, além disso, os desgastes diários e os problemas encontrados na realização do trabalho favorecem o surgimento do estresse e quando não cuidado, o profissional da Psicologia pode se tornar uma vítima do Burnout.

A autora ressalta também que, embora haja indícios de que a prevalência de Burnout no campo da Psicologia seja alta, ainda há poucas pesquisas que possam comprovar tal afirmação, principalmente pesquisas com profissionais brasileiros, nesse sentido é preciso que mais investigações sejam elaboradas (Biehl, 2009).

As expectativas em relação à profissão são criadas antes mesmo desse profissional entrar de fato em contato com as atividades práticas da área, se iniciando, em alguns casos, durante a escolha pelo curso de Psicologia. Meira e Nunes (2005) salientam que as pessoas têm uma concepção acerca do psicólogo que não condiz com a realidade, já que esse profissional é visto como um ser que tem o "poder" de solucionar magicamente o problema dos pacientes. Para as mesmas autoras, essa visão acerca do psicólogo pode contribuir para a escolha de muitos estudantes pela profissão, além do mais, escolhem o curso de Psicologia por acreditar que poderão conhecer melhor o ser humano e ajudá-los em todas as suas demandas (modelo assistencialista).

Diante dessa percepção, os estudantes entram na graduação com fantasias e expectativas sobre o curso e sobre a atuação profissional, acreditando que terão que lidar apenas com o paciente no contexto clínico, porém, no decorrer do curso acabam se deparando com outros campos de atuação e quando esses não estão preparados podem se sentir inseguros, com sentimentos de dúvida quanto à escolha profissional. Uma vez que esse estudante continue sua formação, precisa lidar com a prática profissional, desenvolvendo atividades em vários campos de atuação por meio dos estágios que, embora sejam essenciais para a formação acadêmica, podem gerar grande sofrimento e conflitos (Rudnicki \& Carlotto, 2007).

As autoras Rudnicki e Carlotto (2007) salientam ainda que muitas vezes ao lidar com a prática do estágio, o aluno se encontra com problemas que não foram abordados em sala de aula; é comum se depararem com situações inesperadas e até mesmo inusitadas ou problemas institucionais, esses fatores podem ser grandes estressores e facilitar o surgimento de sentimento de ansiedade, medos, insegurança, sentimento de inferioridade e diversas dúvidas sobre a forma de intervenção. A dificuldade em adaptarem-se às 
questões relacionadas à prática profissional e por vezes, a incerteza da escolha profissional, também pode gerar sofrimento e estresse, sendo que esses fatores podem contribuir posteriormente para problemas profissionais, como as próprias relações no ambiente de trabalho e a forma como esse profissional prestará o cuidado ao paciente (Tomaschewski-Barlem et al., 2014).

Além do estágio o aluno também precisa lidar com a sobrecarga de estudos, com isso, muitos estudantes se queixam de não ter tempo para ficar com a família, com os amigos, realizarem atividades sociais, o que pode trazer sentimento de esgotamento psíquico (Ferraz, Cardona, \& Monte, 2009). Os autores lembram também que a demanda por uma carga maior de estudo se faz necessária diante da necessidade de constante atualização, já que o mercado de trabalho está cada vez mais competitivo. Essa competitividade, muitas vezes, se traduz na sala de aula, gerando conflitos e acarretando problemas emocionais.

Foi realizado um estudo por Tarnowski e Carlotto (2007) composto de uma amostra de 66 estudantes do curso de Psicologia de uma universidade particular da região metropolitana de Porto Alegre, dos quais 33 estudantes eram ingressantes no curso e os outros 33 participantes cursavam o último ano da graduação. Esse estudo indicou que os estudantes que cursavam o último ano apresentavam maior sentimento de desgaste quando comparados aos estudantes que estavam no primeiro ano de curso. Além de aplicarem o questionário Maslach Burnout Inventory-Student Survey (MBI-SS) as pesquisadoras utilizaram um questionário sociodemográfico, por meio deste, pode-se verificar também que $61,3 \%$ dos estudantes que participaram da pesquisa precisam conciliar a graduação com o trabalho, o que pode influenciar no desgaste emocional.

Resultados semelhantes foram encontrados em uma pesquisa transversal realizada com 282 estudantes de uma universidade particular da cidade de São Paulo, da qual participaram estudantes do $1^{\circ}$ ano (68 estudantes), $2^{\circ}$ ano (45 estudantes), $3^{\circ}$ ano (65 estudantes), $4^{\circ}$ ano (41 estudantes) e $5^{\circ}$ ano (63 estudantes).
Nesse estudo, também foi aplicado o MBI-SS e verificou-se que os estudantes que cursavam o $5^{\circ}$ ano apresentaram diferenças quanto à exaustão emocional, descrença e ineficácia profissional se comparados aos estudantes que estavam no início do curso, sendo que o nível de exaustão e descrença foi maior nos estudantes que estavam no fim da graduação; já a ineficácia profissional teve média maior nos estudantes que estavam no início do curso (1 ${ }^{\circ}$ ano) (Fogaça et al., 2012).

Os resultados obtidos pelas pesquisas de Tarnowski e Carlotto (2007) e Fogaça et al. (2012), mostraram que os estudantes de Psicologia que cursam o $5^{\circ}$ ano da graduação estão mais propensos à exaustão emocional. Tal fato pode ser em decorrência dos fatores citados por Carlotto et al. (2006), Ferraz et al. (2009), Rudnicki e Carlotto (2007) e Tarnowski e Carlotto (2007), como a carga excessiva de estudo, frustrações, medo e insegurança diante do contato com a realidade profissional, problemas com as realidades institucionais (falta de estrutura, processos burocráticos, despreparo, etc.), além de ansiedade frente ao mercado de trabalho e menor contato familiar e social devido à demanda dos estudos.

Desta forma o aluno pode apresentar diversas dificuldades no final da graduação, por isso, há importância de maiores investigações, já que mesmo antes de estarem formados, alguns estudantes podem apresentar exaustão e características relacionadas ao Burnout (Tarnowski, \& Carlotto, 2007). Fogaça et al. (2002) concordam com os autores e salientam que além de necessárias mais investigações acerca da síndrome de Burnout em estudantes de Psicologia, também é preciso investigar os impactos que o Burnout pode ter diante da saúde mental do futuro psicólogo.

Assim, o objetivo da pesquisa foi investigar a prevalência do nível de síndrome de Burnout em estudantes de Psicologia em diferentes semestres da graduação. Bem como, investigar se há diferença do nível da síndrome entre o sexo dos participantes, entre os participantes que trabalham e os que não trabalham, entre as idades dos participantes, entre o estado civil dos estudantes e diferentes quantidades de disciplinas. 


\section{Método}

\section{Local}

A coleta de dados foi realizada em uma universidade particular localizada em uma cidade do interior do estado de São Paulo.

\section{Participantes}

Participaram do estudo 123 estudantes universitários do curso de Psicologia. A amostra foi composta por todos os estudantes que estavam presentes na sala de aula no dia da aplicação dos instrumentos de pesquisa. Do total de estudantes apenas 111 responderam corretamente todos os campos dos questionários; os 12 questionários que não estavam em conformidade foram descartados. A média de idade dos participantes foi de 23,5 anos $(D P=7,04)$, sendo que $87,7 \%$ da amostra total eram do sexo feminino.

\section{Instrumentos}

\section{Questionário Sociodemográfico}

O primeiro instrumento aplicado foi um questionário proposto por Carlotto et al. (2006) e foi elaborado tendo como base referencial a teoria sobre o tema. Tal questionário teve como objetivo analisar variáveis sociodemográficas (idade, sexo, estado civil, ocupação, presença de filhos), variáveis acadêmicas (semestre atual, quantidade de disciplinas cursadas atualmente, se possui outra graduação, experiência na área da saúde) e variáveis psicossociais (satisfação com o curso, pensamento de abandonar o curso, prática de atividade física e lazer). Para essa pesquisa utilizou-se também, o inventário MBI-SS.

\section{Maslach Burnout Inventory - Student Survey (MBI-SS)}

O Inventário Maslach Burnout Inventory Student Survey, teve sua versão desenvolvida após verificar a necessidade de investigar o Burnout em estudantes, já que o inventário original (MBIMaslach Burnout Inventory), já tinha sido adaptado para verificar a síndrome em profissionais que trabalhavam diretamente em contato com pessoas (MMI- HSS, Maslach Burnout Inventory - General Survey), e também fora adaptado para profissionais que não trabalham diretamente com outras pessoas (MBI-GS, Maslach Burnout Inventory - General Survey) (Carlotto \& Câmara, 2006).

O MBI-SS adaptado por Schaufeli, Leiter, Maslach, e Jackson (1996) é composto por 15 questões auto-aplicáveis por meio de uma escala Likert, variando de 0 a 6 , onde 0 corresponde a "Nunca", 1 corresponde a "uma vez ao ano ou menos", 2 corresponde a "uma vez no mês ou menos", 3 corresponde a "algumas vezes ao mês", 4 "uma vez por semana", 5 "algumas vezes por semana" e 6 corresponde a "todos os dias" (Carlotto et al., 2006). De acordo com os autores o instrumento encontra-se separado por três partes, onde exaustão emocional abrange 05 itens, despersonalização agrupa 04 itens e eficácia profissional 06 itens.

Para a verificação das características psicométricas do inventário foi realizado um estudo com 514 estudantes brasileiros, da região metropolitana de Porto Alegre; todos os estudantes estavam regularmente matriculados em cursos da área da saúde: a idade média dos sujeitos participantes da pesquisa foi de 26 anos (Carlotto \& Câmara, 2006). As evidências de validade interna apresentaram alpha de Cronbach de 0,81 para exaustão emocional, 0,74 para eficácia profissional e 0,59 para descrença, indicando que no último quesito a fidedignidade teve uma validade moderada.

Segundo Carlotto e Câmara (2006), a validade do construto foi obtida por meio da Análise Fatorial Exploratória, com método de extração de fatores utilizando componentes principais com rotação Oblimin direto. De acordo com as autoras, encontraram-se três fatores que possibilitaram identificar uma distribuição fatorial bem delimitada. O primeiro fator, exaustão 
emocional, explicou 31,88\% da variância; o segundo fator, eficácia profissional, explicou $13,61 \%$ da variância; e, por último, o terceiro fator, descrença, explicou 8,82\% da variância. De acordo com Carlotto e Câmara (2006, p.171), "os 3 fatores obtidos agrupam os itens referentes à exaustão emocional, eficácia profissional e descrença, respectivamente. Com base na distribuição de cargas fatoriais, pode-se considerar que todos os 3 fatores aparecem diferenciados com relação a sua unidimensionalidade".

\section{Procedimento}

Primeiramente, foi realizado o contato com a instituição em que foi realizada a pesquisa. A posteriori, a pesquisa foi submetida ao Comitê de Ética em pesquisa; após sua aprovação, iniciouse a aplicação dos testes. A pesquisadora fez a apresentação da pesquisa, informando sobre todos os processos, inclusive a questão do sigilo. Após a apresentação foi entregue aos estudantes o Termo de Consentimento Livre e Esclarecido para aqueles que aceitaram a participação.

A aplicação da pesquisa se deu de forma coletiva em cada sala, e foi realizada em duas etapas: primeiramente foi aplicado um questionário sociodemográfico e, em seguida, foi realizada a aplicação do Maslach Burnout Inventory - Student Survey (MBI-SS). O tempo de aplicação foi de aproximadamente 30 minutos.

\section{Resultados e discussão}

Os dados coletados por meio do Maslach Burnout Inventory - Student Survey (MBI-SS) foram analisados pela estatística descritiva, considerando o grupo de participantes em seu total e também divididos de acordo com o semestre da graduação, estabelecido pelos dados obtidos com o Questionário Sociodemográfico. Foi analisado o efeito das variáveis: idade, gênero, estado civil e situação profissional por meio dos testes estatísticos $t$ de Student e Análise de Variância - ANOVA. Assumiu-se como hipótese dos testes $t$ que o h0 é de que os fatores são iguais, ou seja, não interferem estatisticamente nos resultados, exemplo: ser do sexo feminino ou do sexo masculino não interfere no resultado e a hipótese alternativa é que ser do sexo masculino ou feminino interfere.
Pode-se verificar que dentre os estudantes participantes a maioria $(84,7 \%)$ correspondia ao estado civil "solteiro", apenas 10,8\% declararam ser casados e a minoria (4,5\%) responderam ser separados, viúvos ou possuir união estável (Tabela 1). Apenas 10,8\% da amostra responderam ter filhos.

Em relação à atividade profissional, 34,2\% da amostra declararam apenas estudar, enquanto $65,8 \%$ da população analisada responderam que além de estudar exerciam atividade laboral. Dos sujeitos investigados $36,9 \%$ pagam os estudos por meio de recursos familiares, a mesma porcentagem (36,9\%), de estudantes utilizava financiamento ou bolsa, já 26,1\% (vinte nove estudantes), pagavam os estudos com os próprios recursos, os dados podem ser vistos na Tabela 2.

Tabela 1

Características sociodemográficas dos estudantes de Psicologia participantes da pesquisa

\begin{tabular}{lcc}
\hline Estado Civil & $N$ & $\%$ \\
\hline Solteiro & 94 & 84,7 \\
Casado & 12 & 10,8 \\
Separado/Viúvo & 04 & 03,6 \\
União Estável & 01 & 00,9 \\
\hline Total & 111 & 100,0 \\
\hline
\end{tabular}


Tabela 2

Recursos usados para pagamento do curso

\begin{tabular}{lcc}
\hline Recursos & $N$ & $\%$ \\
\hline Com recursos familiares & 41 & 36,9 \\
Com recursos próprios & 29 & 26,1 \\
Com financiamento ou bolsa & 41 & 36,9 \\
\hline Total & 111 & 100 \\
\hline
\end{tabular}

Dos 111 estudantes analisados, 43\% cursavam o primeiro semestre da graduação, $28 \%$ cursavam o quinto semestre e $29 \%$ estavam no décimo semestre do curso, ou seja, a maioria dos estudantes estava no início da vida universitária. Conforme pode ser visualizado na Figura 1, a maioria dos estudantes iniciou o curso no ano de 2015 (41,4\%), já a menor parcela da amostra (0,9\%) teve o ingresso na graduação no ano de 2007. Outros 20,7\% e $23,4 \%$ dos estudantes iniciaram o curso no ano de 2011 e 2013, respectivamente.

Os resultados obtidos, por meio da análise descritiva, também mostraram que os estudantes participantes da pesquisa estavam cursando em média 5 disciplinas $(D P=1,4)$ no momento em que os dados foram coletados. Foi possível verificar ainda que, $51,4 \%$ dos estudantes estavam realizando atividade prática ou estágio no semestre em que estavam cursando, enquanto $48,6 \%$ da amostra não realizavam tais práticas. Em relação à experiência na área da saúde, 20,7 \% dos estudantes responderam ter experiência profissional nessa área, já 79,3\% não tinham experiência profissional na área da saúde.
Do total de participantes, somente 13 estudantes $(11,7 \%)$, possuíam outro curso superior, observou-se também que 5,4\% (correspondentes a seis estudantes) dos participantes, realizavam outro curso complementar na área.

Ao que se refere à satisfação com o curso, 99,1\% dos estudantes relataram estar satisfeitos, o que revela que esses estudantes foram assertivos em relação à escolha profissional. Por outro lado, 13,5\% dos participantes responderam que já pensaram em trocar ou abandonar o curso, sendo que a maioria $(n=8)$ desses estudantes cursava o $9^{\circ}$ semestre, esse resultado pode indicar que no decorrer dos semestres as dúvidas em relação ao curso escolhido são mais evidentes que no início da graduação.

A escolha pelo primeiro curso geralmente ocorre no final da adolescência, período de diversas transformações e desafios na vida do indivíduo, nessa época há diversos fatores que podem influenciar na escolha profissional e essa decisão nem sempre é assertiva. Em um estudo realizado a fim de verificar a percepção de alunos sobre o abandono do curso superior, alguns estudantes relataram que a escolha profissional foi realizada

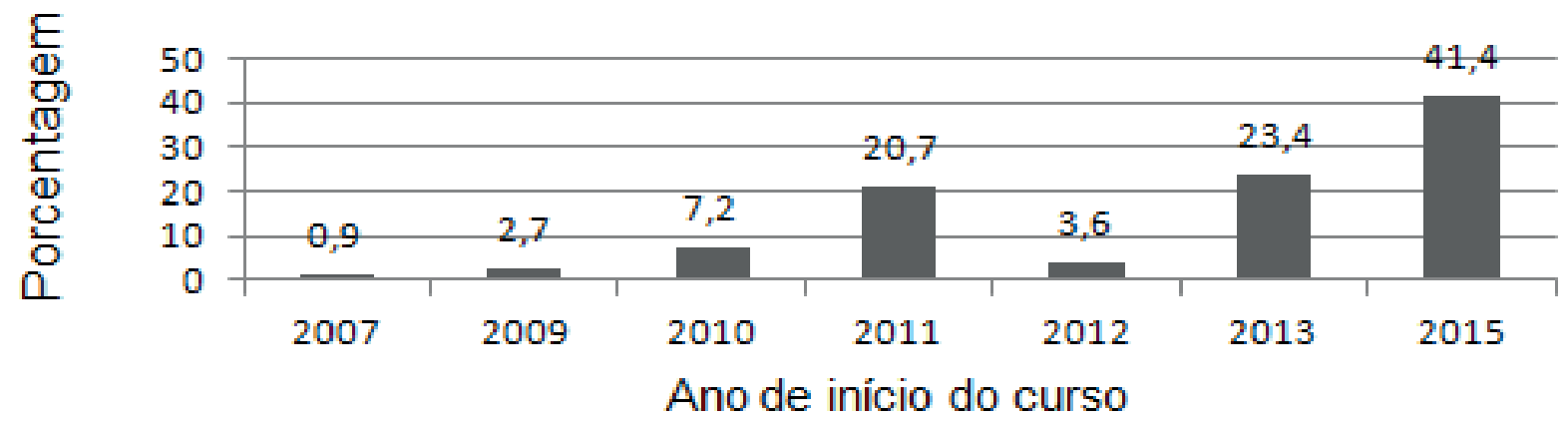

Figura 1. Características demográficas segundo o ano de início do curso. 
em decorrência de pressões e essa escolha foi vista como negativa por eles, já que muitos estudantes não possuíam informações necessárias a respeito do curso escolhido, segundo eles, a escolha foi realizada com o intuito de iniciarem rapidamente uma graduação (Bardagi \& Hutz, 2009).

$\mathrm{Na}$ visão de Igue, Bariani, e Milanesi (2008) o estudante ingressa na universidade com grandes expectativas em relação ao curso e a vida acadêmica, tais expectativas por vezes são equivocadas, gerando dúvidas e sentimento de insatisfação. Além disso, o estudante tende a iniciar a graduação entusiasmado pela conquista da vaga no vestibular, entretanto, no decorrer do tempo as decepções em relação ao curso, contribuem para que o aluno repense sua escolha profissional (Bardagi, Lassance, \& Paradiso, 2003).

Já nos últimos semestres, os estudantes tiveram a oportunidade de vivenciar a atuação profissional por meio dos diversos estágios práticos, pode-se pensar que, a ideia de trocar ou abandonar o curso pode ser um indicativo da dificuldade desses estudantes em se adaptarem à profissão. Bardagi e Hutz (2009) encontraram em seu estudo alguns fatores que foram decisivos para a desistência da graduação, entre esses fatores estavam o desconhecimento da realidade profissional e desgaste emocional em decorrência da tentativa de adaptação do curso. A dificuldade de adaptação pode gerar sofrimento e estresse nesses indivíduos, o que futuramente pode contribuir para o surgimento de problemas profissionais e facilitar o surgimento da SB (TomaschewskiBarlem et al., 2013, 2014),
Neste estudo, os dados obtidos por meio do teste $t$ de Student reforçam o impacto da incerteza profissional na vida dos alunos, já que os resultados revelaram que os estudantes que já pensaram em abandonar o curso $(M=$ 8,33) possuem diferença significativa, $t=(111)$ $=3,273, p=0,001$, no fator descrença quando comparado aos sujeitos que nunca pensaram em abandonar o curso $(M=4,76)$, conforme a Tabela 3 . Tal resultado sugere que esses estudantes, apresentam maior distanciamento em relação aos estudos e pouca confiança no ensino (Carlotto, \& Câmara, 2006). Ratificando os achados das autoras, Bardagi e Hutz (2009) revelaram por meio de um estudo acerca da evasão universitária, que durante a graduação os alunos foram se distanciando dos estudos gradualmente até culminarem na desistência da graduação.

O resultado encontrado valida o de Carlotto et al. (2006), no qual as autoras encontraram maior sentimento de descrença, nos sujeitos que disseram já ter pensado em abandonar o curso. Para as autoras, esse pensamento pode tanto revelar indícios da síndrome quanto influenciar o surgimento dela, já que o sujeito que pensou ou pensa em abandonar o curso pode estar vivenciando diversos conflitos emocionais.

Ainda em relação à dimensão descrença, foi verificado que no nível de $5 \%$, existe evidência estatística significativa entre os grupos divididos em função do sexo. Desta forma, graduandos do sexo feminino apresentaram maior sentimento de descrença $t=(111)=2,029, p=0,045 \mathrm{em}$ relação ao sexo masculino. $O$ que sugere que as

Tabela 3

Diferença de média dos fatores do MBI-SS por intenção ou não de abandono do curso

\begin{tabular}{|c|c|c|c|c|c|c|}
\hline Fatores & $\begin{array}{l}\text { Intenção de } \\
\text { abandono do } \\
\text { curso }\end{array}$ & $N$ & Média & Desvio Padrão & $t$ & $p$ \\
\hline \multirow{2}{*}{ Exaustão } & $\operatorname{Sim}$ & 15 & 18,60 & 7,199 & \multirow{2}{*}{1,124} & \multirow{2}{*}{0,264} \\
\hline & Não & 96 & 16,21 & 7,734 & & \\
\hline \multirow{2}{*}{ Descrença } & $\operatorname{Sim}$ & 15 & 8,33 & 5,728 & \multirow{2}{*}{3,273} & \multirow{2}{*}{0,001} \\
\hline & Não & 96 & 4,76 & 3,592 & & \\
\hline \multirow{2}{*}{ Eficácia Profissional } & Sim & 15 & 27,73 & 5,049 & \multirow{2}{*}{$-0,844$} & \multirow{2}{*}{0,400} \\
\hline & Não & 96 & 28,80 & 4,483 & & \\
\hline
\end{tabular}


Tabela 4

Diferença de média dos fatores do MBI-SS por gênero

\begin{tabular}{|c|c|c|c|c|c|c|}
\hline Fatores & Sexo & $N$ & Média & Desvio Padrão & $t$ & $p$ \\
\hline \multirow{2}{*}{ Exaustão } & Feminino & 94 & 17,06 & 0,792 & \multirow{2}{*}{1,734} & \multirow{2}{*}{0,086} \\
\hline & Masculino & 17 & 13,59 & 1,736 & & \\
\hline \multirow{2}{*}{ Descrença } & Feminino & 94 & 5,57 & 0,442 & \multirow{2}{*}{2,029} & \multirow{2}{*}{0,045} \\
\hline & Masculino & 17 & 3,41 & 0,536 & & \\
\hline \multirow{2}{*}{ Eficácia Profissional } & Feminino & 94 & 28,62 & 0,467 & \multirow{2}{*}{$-0,220$} & \multirow{2}{*}{0,826} \\
\hline & Masculino & 17 & 28,88 & 1,172 & & \\
\hline
\end{tabular}

alunas do curso, possuem mais atitudes cínicas e distanciadas em relação aos estudos (Maia et al., 2012) se comparado aos estudantes do sexo masculino, os dados podem ser vistos na Tabela 4.

Essa diferença pode estar relacionada com o número de estudantes do sexo feminino $(\mathrm{n}=94)$ ser maior se comparado sexo masculino ( $\mathrm{n}=$ 17), visto que, não foram encontrados estudos em que a amostra de estudantes fosse composta por número equivalente de homens e mulheres, comparando de forma igualitária essa população. Contudo, a pesquisa bibliográfica de Matos e Junior (2008), denominada "A incorporação do gênero no estudo da Síndrome de Burnout", na qual os autores analisaram a relação do gênero e a síndrome de Burnout nos profissionais de enfermagem inseridos no contexto hospitalar, revelou que, mesmo sendo a maior parte da amostra constituída por profissionais do sexo feminino, os homens tiveram maior pontuação no fator despersonalização do que as mulheres. Os mesmos autores salientam que, a área da saúde é constituída predominantemente por mulheres, o que no caso, pode esconder a influência dessa variável na $S B$.

Esse resultado pode ser interpretado também quanto aos estudantes de Psicologia, já que esse curso também é predominantemente composto por mulheres (Yamamoto \& Seixas, 2011), o que comprova uma tendência da feminilização da Psicologia, e que igualmente foi evidenciado nesse estudo.

Diferenças também foram encontradas ao analisar as dimensões do Burnout com a variável referente à realização de outro curso superior. As análises realizadas por meio do teste $t$ de Student, não mostraram diferença estatisticamente significativa no fator descrença, $t=(111)=-0,658, p$ $=0,512$ entre os estudantes que já possuem outra graduação, contudo, dado ao acaso, os sujeitos que não possuem outra graduação, apresentaram médias maiores $(M=5,34)$ do que aqueles que já fizeram outro curso superior $(M=4,54)$. Também dado ao acaso, encontrou-se médias maiores na dimensão exaustão emocional naqueles estudantes que não possuem outro curso superior $(M=16,62$ versus 15,85 ), o que indica nesses estudantes maior sentimento de desgaste e distanciamento em relação aos estudos conforme menciona essa dimensão (Carolotto et al., 2009).

Já em relação à dimensão eficácia profissional, os resultados revelaram diferenças significativas na variável "possuir outro curso superior" $t=$ $(111)=2,001, p=0,048$, conforme resultados apresentados na Tabela 5. Estudantes que já possuíam outra graduação tiveram escores mais elevados nessa dimensão do que aqueles que estão na primeira vivência acadêmica. $\mathrm{O}$ resultado sugere que os estudantes que já possuem experiência na vida universitária tendem a se sentir mais competentes em relação aos estudos do que aqueles que estão cursando a primeira graduação. Nesse sentido, pode-se sugerir que a escolha do segundo curso tenha sido realizada de forma mais assertiva, contribuído para uma melhor percepção acerca dos estudos, além disso, por já ter uma vivência universitária anterior, esse estudante está mais adaptado às rotinas de 
Tabela 5

Diferença de média dos fatores do MBI-SS em relação à realização de graduação anterior

\begin{tabular}{lcccccc}
\hline Fatores & Possui outro curso superior? & $N$ & Média & Desvio Padrão & $t$ & $p$ \\
\hline \multirow{2}{*}{ Exaustão } & Sim & 13 & 15,85 & 0,792 & $-0,341$ & 0,734 \\
\multirow{2}{*}{ Descrença } & Não & 98 & 16,62 & 1,736 & & \\
\multirow{2}{*}{ Eficácia Profissional } & Sim & 13 & 4,54 & 0,442 & $-0,658$ & 0,512 \\
& Não & 98 & 5,34 & 0,536 & & \\
& Sim & 13 & 31 & 0,467 & 2,001 & 0,048 \\
\hline
\end{tabular}

estudo e as exigências acadêmicas.

Em um estudo realizado com o objetivo de conhecer o perfil dos alunos de Psicologia (Bosi \& Elias, 2000), verificou-se que dentre os 442 participantes, 112 já possuíam diploma em outra graduação, o estudo mostrou que para esses estudantes, a entrada no curso de Psicologia partiu de um desejo já existente e esse ingresso foi visto como uma complementação da graduação anterior. No mesmo estudo, os estudantes revelaram que os sentimentos vividos por eles em relação a essa outra vivência acadêmica eram de maior aproveitamento no curso, além de realização pessoal e profissional, sendo que esses sentimentos superavam as frustrações encontradas no decorrer do curso.

Desta forma, pode-se comparar o estudo realizado por Bosi e Elias (2000) e o presente estudo ao que se refere à eficácia profissional, já que em ambos os estudos, os alunos que realizaram outra graduação se sentiam mais eficazes em relação aos estudos e tendiam a aproveitar mais o curso que estavam realizando. Ademais, os estudantes que estavam cursando Psicologia como segunda graduação tinham em média 30 anos ( $D P=10,03$ ), ou seja, a entrada em outro curso ocorreu no início da vida adulta (Papalia, Olds, \& Feldmam, 2006), de acordo com as autoras esse costuma ser um período transitório na vida do sujeito: "em vez de consolidar sua escolha ocupacional inicial, as pessoas que seguem o padrão transitório tentam alcançar uma melhor correspondência entre o que sabem fazer, o que querem e esperam de seu trabalho e o que estão recebendo dele" (p.617).
Neste caso, pode-se pensar que os estudantes dessa pesquisa estavam vivenciando esse período transitório e a identificação profissional com o curso escolhido suscitou o sentimento de eficácia em relação aos estudos.

Contudo em relação às dimensões do Burnout e a idade dos participantes, os resultados indicaram diferença estatisticamente significativa nas dimensões descrença e exaustão emocional. Os resultados apresentados na Tabela 6 revelaram que os estudantes com idade entre 27 e 36 anos apresentaram médias maiores nessas duas dimensões quando comparados a outros grupos de estudantes. Os estudantes dessa faixa etária estavam cursando em sua maioria $(n=5)$ o $5^{\circ}$ semestre da graduação, período no qual esse estudante já teve a vivência em alguns estágios práticos, o que pode favorecer o surgimento de dúvidas em relação ao curso escolhido e acarretar um distanciamento dos estudos. Os resultados também mostraram que os estudantes dessa faixa etária também apresentam maior exaustão emocional quando comparado aos outros estudantes. Pode-se supor que a falta de experiência e a incapacidade do jovem em lidar com uma nova realidade, sejam fatores que podem acarretar em maiores índices de desgaste emocional. Os resultados podem ser vistos na Tabela 6.

Para ser caracterizado como Burnout é necessário que o indivíduo possua altos escores nos fatores exaustão emocional e descrença e escore baixo no fator eficácia profissional, desta forma os resultados não indicaram a prevalência da síndrome de Burnout nos estudantes da pesquisa. 
Tabela 6

Diferenças de médias das dimensões do Burnout por grupos de idade

\begin{tabular}{lccccc}
\hline Fatores & Idade & $N$ & Média & $F$ & $p$ \\
\hline \multirow{3}{*}{ Exaustão emocional } & $17-26$ & 92 & 15,99 & & \\
& $27-36$ & 13 & 22,31 & 4,67 & 0,004 \\
& $37-46$ & 2 & 20 & & \\
Descrença & $47-53$ & 4 & 8,5 & & \\
& $17-26$ & 92 & 4,76 & & \\
& $27-36$ & 13 & 7,85 & 4,395 & \\
Eficácia profissional & $37-46$ & 2 & 12 & & \\
& $47-53$ & 4 & 4,5 & & \\
& $17-26$ & 92 & 28,7 & & \\
\hline
\end{tabular}

$p<0,05$ de acordo com o teste de Tuckey HSD.

Os dados mostraram que a maioria dos estudantes teve escore mediano nos fatores exaustão emocional e descrença (48,65\% e 45,95\% respectivamente) e escore alto no fator eficácia profissional (84,68\%), conforme apresentado na Tabela 7, o que indica que tanto os estudantes iniciantes quanto os estudantes concluintes se sentem eficazes como estudantes. Em relação à eficácia profissional o resultado vai ao encontro da pesquisa realizada por Maia et al. (2012), na qual os pesquisadores também encontraram escores altos nessa dimensão, entretanto, a presente pesquisa se difere quanto às dimensões exaustão emocional e descrença, já que os escores encontrados pelos mesmos autores foram alto e médio, respectivamente.

Por fim, os testes de Análise de Variância indicaram que não houve diferença estatisticamente significativa das dimensões de Burnout entre os estudantes dos diferentes níveis da graduação.

Esses resultados se diferem de pesquisas realizadas por Fogaça et al. (2012) e Tarnowski e Carlotto (2007), no qual os pesquisadores encontraram diferenças significativas das dimensões do Burnout entre os estudantes ingressantes e estudantes concluintes do curso de Psicologia. Sendo que, nos estudos realizados por Fogaça et al. (2012), os resultados apontaram a prevalência da síndrome nos estudantes concluintes do curso de Psicologia. Já os resultados obtidos por Tarnowski e Carlotto (2007) confirmaram em parte a hipótese de que as dimensões do Burnout se diferenciavam entre os níveis da graduação, já que a dimensão exaustão emocional foi a única que apresentou diferença significativa entre os grupos, evidenciando que os estudantes concluintes do curso se sentiam mais desgastados e cansados do que os estudantes que estavam iniciando a graduação.

A seguir, serão apresentadas as análises descritivas referentes às dimensões do Burnout. A estatística descritiva da dimensão exaustão emocional mostra que, a maioria dos estudantes participantes da pesquisa se sente emocionalmente esgotada e cansada para enfrentar outro dia de estudos, o que pode assinalar uma possível sobrecarga emocional, além disso, pode ser um indicativo da síndrome se tais sentimentos se potencializarem e vierem acompanhados de alta descrença e baixa realização profissional, nesse sentido, é preciso estar alerta aos sentimentos vivenciados por esses estudantes e tomar medidas para prevenir o surgimento da SB nesse futuro profissional. Os dados podem ser vistos na Tabela 8 .

Já as análises descritivas da dimensão descrença, mostram quea maioria dos estudantes "nunca" se sente 
Tabela 7

Escores das dimensões do Burnout do MBI-SS

\begin{tabular}{llcc}
\hline Dimensões & Escores & $N$ & $\%$ \\
\hline \multirow{2}{*}{ Exaustão Emocional } & baixa $(<16)$ & 46 & 41,44 \\
& média $(16-25)$ & 54 & 48,65 \\
& alta $(>25)$ & 11 & 9,91 \\
Descrença & baixa $(<3)$ & 37 & 33,33 \\
& média $(3-8)$ & 51 & 45,95 \\
Eficácia Profissional & alta $(>8)$ & 23 & 20,72 \\
& baixa $(>41)$ & 0 & 0 \\
& média $(34-41)$ & 17 & 15,32 \\
& alta $(<34)$ & 94 & 84,68 \\
\hline
\end{tabular}

Tabela 8

Estatísticas descritivas dos itens do Burnout, fator exaustão emocional

\begin{tabular}{|c|c|c|c|c|c|c|c|c|c|}
\hline \multirow[b]{2}{*}{ Afirmações por Fator } & \multicolumn{5}{|c|}{ Estatísticas } & \multicolumn{3}{|c|}{ Concordância } & \multirow[b]{2}{*}{$\begin{array}{l}\text { Todos } \\
\text { os dias }\end{array}$} \\
\hline & Média & $\begin{array}{l}\text { Desvio } \\
\text { Padrão }\end{array}$ & Nunca & $\begin{array}{c}\text { Uma vez } \\
\text { ao ano ou } \\
\text { menos }\end{array}$ & $\begin{array}{l}\text { Uma vez } \\
\text { ao mês } \\
\text { ou menos }\end{array}$ & $\begin{array}{l}\text { Algumas } \\
\text { vezes ao } \\
\text { mês }\end{array}$ & $\begin{array}{l}\text { Uma } \\
\text { vez por } \\
\text { semana }\end{array}$ & $\begin{array}{c}\text { Algumas } \\
\text { vezes por } \\
\text { semana }\end{array}$ & \\
\hline $\begin{array}{l}\text { 1. Sinto-me } \\
\text { emocionalmente } \\
\text { esgotado pelos meus } \\
\text { estudos. }\end{array}$ & 3,22 & 1,68 & $\begin{array}{c}7 \\
6,30 \%\end{array}$ & $\begin{array}{c}13 \\
11,07 \%\end{array}$ & $\begin{array}{c}18 \\
16,20 \%\end{array}$ & $\begin{array}{c}26 \\
23,40 \%\end{array}$ & $\begin{array}{c}11 \\
9,90 \%\end{array}$ & $\begin{array}{c}30 \\
27,00 \%\end{array}$ & $\begin{array}{c}6 \\
5,40 \%\end{array}$ \\
\hline $\begin{array}{l}\text { 4. Sinto-me esgotado } \\
\text { no fim de um dia em } \\
\text { que tenho aula. }\end{array}$ & 3,9 & 1,86 & $\begin{array}{c}7 \\
6,30 \%\end{array}$ & $\begin{array}{c}9 \\
8,10 \%\end{array}$ & $\begin{array}{c}11 \\
9,90 \%\end{array}$ & $\begin{array}{c}15 \\
13,50 \%\end{array}$ & $\begin{array}{c}14 \\
12,60 \%\end{array}$ & $\begin{array}{c}29 \\
26,01 \%\end{array}$ & $\begin{array}{c}26 \\
23,40 \%\end{array}$ \\
\hline $\begin{array}{l}\text { 6. Sinto-me cansado } \\
\text { quando me levanto } \\
\text { para enfrentar outro } \\
\text { dia de aula. }\end{array}$ & 3,47 & 1,91 & $10,80 \%$ & $8,10 \%$ & $11,70 \%$ & $18,00 \%$ & $8,10 \%$ & $30,06 \%$ & $12,60 \%$ \\
\hline $\begin{array}{l}\text { 8. Estudar e } \\
\text { frequentar as aulas } \\
\text { são, para mim, um } \\
\text { grande esforço. }\end{array}$ & 2,71 & 2,01 & $19,80 \%$ & $12,60 \%$ & $12,60 \%$ & $22,50 \%$ & $9,90 \%$ & $9,00 \%$ & $13,50 \%$ \\
\hline $\begin{array}{l}\text { 12. Sinto-me } \\
\text { consumido pelos } \\
\text { meus estudos. }\end{array}$ & 3,23 & 1,98 & $12,60 \%$ & $9,90 \%$ & $14,40 \%$ & $18,90 \%$ & $7,20 \%$ & $22,50 \%$ & $14,40 \%$ \\
\hline
\end{tabular}

descrente em relação aos estudos, ou seja, o resultado mostra que o sentimento de distanciamento em relação aos estudos não foi percebido na amostra pesquisada, o que descarta a prevalência da SB.
Os resultados encontrados nessa pesquisa vão ao encontro dos resultados obtidos por Osternack, Gonçalves, e Amorim (2007), na qual a maioria dos estudantes responderam que "nunca" se sentiam 
descrentes. O mesmo estudo revelou que naqueles estudantes também não havia prevalência da síndrome de Burnout, todavia as autoras também alertam sobre um possível indicativo da síndrome, já que os mesmos obtiveram pontuações medianas em exautão emocional. Os resultados das análies descritivas da dimensão descrença" são apresentados na Tabela 9.

Por fim, ao que e se refere à eficácia profissional, as análises descritivas dessa dimensão revelaram que os estudantes se sentem competentes em relação aos estudos "algumas vezes por semana", o que mostra que esses estudantes têm uma percepção de aproveitamento em relação ao curso. O resultado encontrado é similar à pesquisa realizada por Osternack et al. (2007) na qual os estudantes responderam que se sentiam eficazes "todos os dias". Os resultados da análise descritiva da dimensão "eficácia profissional" podem ser vistos na Tabela 10.

Tabela 9

Estatísticas descritivas dos itens do Burnout, dimensão Descrença

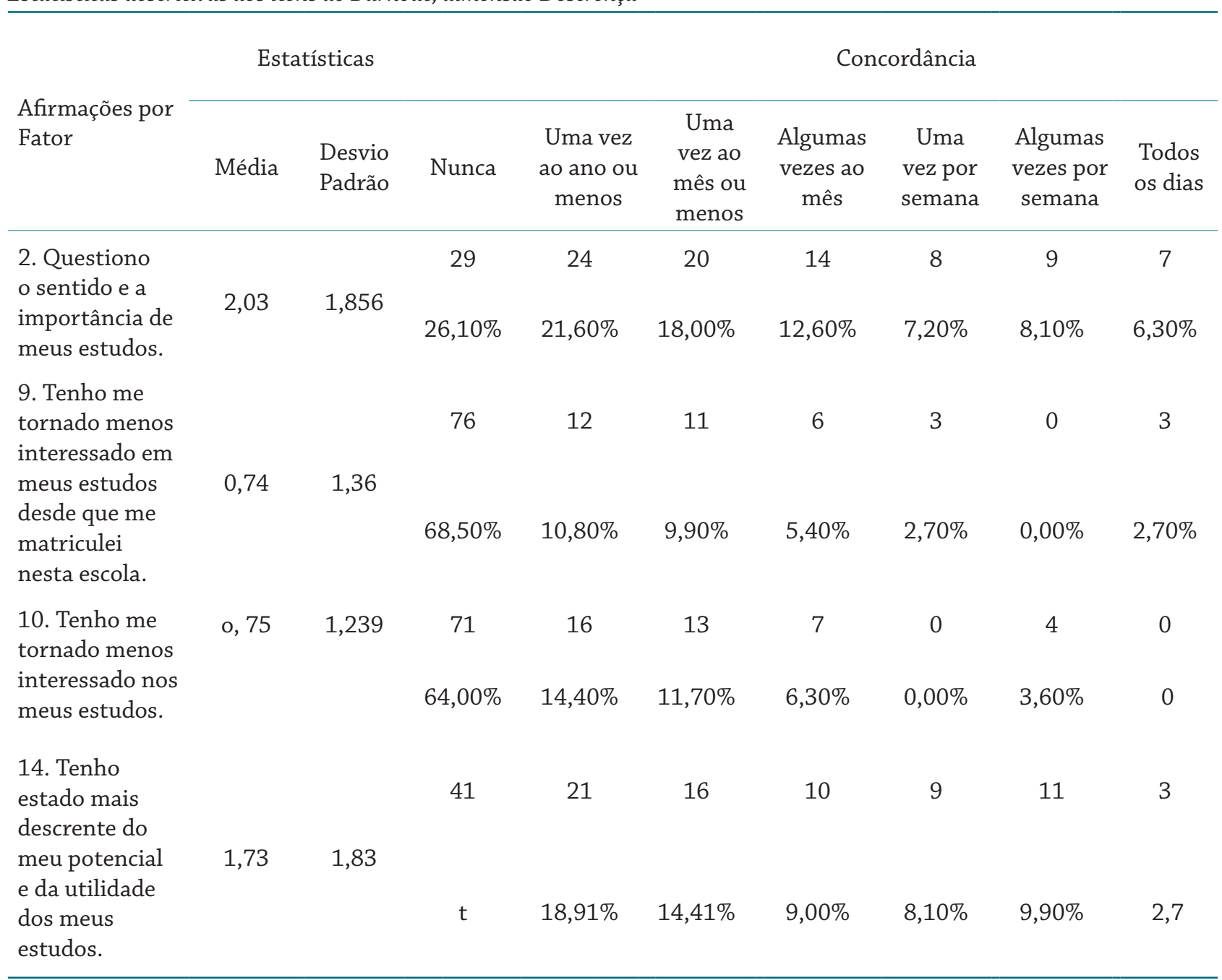


Tabela 10

Estatísticas descritivas dos itens do Burnout, dimensão eficácia profissional.

\begin{tabular}{|c|c|c|c|c|c|c|c|c|c|}
\hline \multirow[b]{2}{*}{$\begin{array}{l}\text { Afirmações por } \\
\text { Fator }\end{array}$} & \multicolumn{3}{|c|}{ Estatísticas } & \multicolumn{6}{|c|}{ Concordância } \\
\hline & Média & $\begin{array}{l}\text { Desvio } \\
\text { Padrão }\end{array}$ & Nunca & $\begin{array}{l}\text { Uma } \\
\text { vez ao } \\
\text { ano ou } \\
\text { menos }\end{array}$ & $\begin{array}{l}\text { Uma } \\
\text { vez ao } \\
\text { mês ou } \\
\text { menos }\end{array}$ & $\begin{array}{c}\text { Algumas } \\
\text { vezes ao } \\
\text { mês }\end{array}$ & $\begin{array}{c}\text { Uma } \\
\text { vez por } \\
\text { semana }\end{array}$ & $\begin{array}{l}\text { Algumas } \\
\text { vezes por } \\
\text { semana }\end{array}$ & $\begin{array}{c}\text { Todos os } \\
\text { dias }\end{array}$ \\
\hline $\begin{array}{l}\text { 3. Tenho } \\
\text { aprendido }\end{array}$ & & & 0 & 1 & 0 & 4 & 8 & 30 & 61 \\
\hline $\begin{array}{l}\text { muitas coisas } \\
\text { interessantes } \\
\text { no decorrer dos } \\
\text { meus estudos. }\end{array}$ & 5,43 & 0,891 & $0,00 \%$ & $0,90 \%$ & 0 & $3,60 \%$ & $7,20 \%$ & $27,00 \%$ & $61,30 \%$ \\
\hline $\begin{array}{l}\text { 5. Durante as } \\
\text { aulas, sinto- }\end{array}$ & & & 0 & 1 & 1 & 17 & 14 & 57 & 21 \\
\hline $\begin{array}{l}\text { me confiante: } \\
\text { entrego as } \\
\text { tarefas prontas } \\
\text { de forma eficaz. }\end{array}$ & 4,69 & 1,034 & $0,00 \%$ & $0,90 \%$ & $0,90 \%$ & $15,30 \%$ & $12,60 \%$ & $51,40 \%$ & $18,90 \%$ \\
\hline $\begin{array}{l}\text { 7. Sinto-me } \\
\text { estimulado (a) }\end{array}$ & & & 0 & 0 & 3 & 2 & 8 & 34 & 64 \\
\hline $\begin{array}{l}\text { quando concluo } \\
\text { com êxito a } \\
\text { minha meta de } \\
\text { estudos. }\end{array}$ & 5,39 & 0,906 & $0,00 \%$ & $0,00 \%$ & $2,70 \%$ & $1,80 \%$ & $7,20 \%$ & $30,00 \%$ & $57,70 \%$ \\
\hline & & & 0 & 0 & 8 & 20 & 14 & 45 & 24 \\
\hline $\begin{array}{l}\text { me um (a) bom } \\
\text { (a) estudante. }\end{array}$ & 4,51 & 1,22 & $0,00 \%$ & $0,00 \%$ & $7,20 \%$ & $18,00 \%$ & $12,60 \%$ & $40,50 \%$ & $21,60 \%$ \\
\hline $\begin{array}{l}\text { 13. Posso, } \\
\text { efetivamente, }\end{array}$ & & & 1 & 2 & 9 & 14 & 16 & 41 & 28 \\
\hline $\begin{array}{l}\text { resolver os } \\
\text { problemas que } \\
\text { surgem nos meus } \\
\text { estudos. }\end{array}$ & 4,5 & 1,381 & $0,90 \%$ & $1,80 \%$ & $8,10 \%$ & $12,60 \%$ & $14,40 \%$ & $36,90 \%$ & $25,20 \%$ \\
\hline $\begin{array}{l}\text { 15. Acredito que } \\
\text { eu seja eficaz }\end{array}$ & & & 0 & 7 & 5 & 30 & 18 & 26 & 25 \\
\hline $\begin{array}{l}\text { na contribuição } \\
\text { das aulas que } \\
\text { frequento. }\end{array}$ & 4,14 & 1,468 & $0,00 \%$ & $6,30 \%$ & $4,50 \%$ & $27,00 \%$ & $16,20 \%$ & $23,40 \%$ & $22,50 \%$ \\
\hline
\end{tabular}




\section{Considerações finais}

O curso de Psicologia, além de exigir uma grande carga em relação aos estudos, também exige que os estudantes cumpram atividades práticas relacionadas à área de atuação. Diante desse cenário, os estudantes acabam se deparando com vários fatores estressantes, no decorrer do curso, o que pode acarretar uma sobrecaga emocional e consequentemente interferir negativamente na saúde mental desses estudantes, inclusive ocasionando a síndrome de Burnout.

Embora o resultado do estudo não tenha revelado a prevalência da síndrome de Burnout nos estudantes de Psicologia, por meio das análises sociodemográficas e das variáveis acadêmicas foi possível verificar a prevalência das dimensões exaustão emocional, descrença e eficácia profissional em alguns grupos de estudantes, contudo, nenhum grupo apresentou as três dimensões conjuntamente.

$O$ resultado do estudo identificou que o sentimento de descrença foi maior naqueles estudantes que já pensaram em abandonar o curso, não possuem outro curso superior, são do sexo feminino e/ou são relativamente jovens. Em relação à variável idade, os estudantes mais jovens também apresentaram maior sentimento de exaustão emocional. Por outro lado, apenas estudantes que possuíam outro curso superior apresentaram maior sentimento de eficácia profissional.

Tais resultados mostram que embora não tenham sido encontrados estudantes com indícios de Burnout, as dimensões presentes no estudo indicam uma sobrecarga emocional e um distanciamento desses estudantes em relação aos estudos, ou seja, verifica-se certo prejuízo na vivência acadêmica desses estudantes, nesse contexto, pode-se pensar que no futuro esses estudantes entrarão no mercado de trabalho com danos em sua saúde psíquica, o que pode prejudicar o desenvolvimento do seu trabalho.

Nesse sentido, é preciso que as universidades se atentem à saúde mental desses futuros psicólogos, traçando ações interventivas sobre esses alunos a fim de minimizar fatores estressores que contribuam para um possível desenvolvimento da síndrome de Burnout nesses futuros profissionais. Nessa perspectiva, pode-se pensar em pesquisas que visem identificar os aspectos geradores de sentimentos relacionados às dimensões do Burnout durante cada etapa do desenvolvimento do curso, além disso, salienta-se também a importância de estudos relacionados à síndrome de Burnout em estudantes de Psicologia que componham uma amostra equivalente de homens e mulheres, já que a maior parte da amostra foi composta por mulheres, o que pode ter enviesado o resultado da pesquisa.

\section{Referências}

Abreu, K. L., Stoll, I., Ramos, L. S., Baumgardt, R. A., \& Kristensen, C. H. (2002). Estresse ocupacional e Síndrome de Burnout no exercício profissional da psicologia. Psicologia: Ciência e Profissão, 22(2), 22-29. doi: 10.1590/S1414-98932002000200004

Araujo, C. G. (2008). A Saúde mental está doente! A Síndrome de Burnout em psicólogos que trabalham em Unidades Básicas de Saúde (Dissertação de Mestrado). Universidade de São Paulo, São Paulo, Brasil.

Bardagi, M. P., \& Hutz, C. S. (2009). Não havia outra saída: percepções de alunos evadidos sobre o abandono do curso superior. PsicoUSF, 14(1), 95-105. Recuperado de http://pepsic.bvsalud.org/pdf/psicousf/v14n1/ v14n1a10.pdf
Bardagi, M. P., Lassance, M. C. P., \& Paradiso, A. C. (2003). Trajetória acadêmica e satisfação com a escolha profissional de universitário em meio de curso. Revista Brasileira Orientação Profissional, 4(1-2), 153-166. Recuperado de http://pepsic.bvsalud.org/pdf/rbop/ v4n1-2/v4n1-2a13.pdf

Biehl, K. A. (2009). Burnout em Psicólogos (Tese de Pós Graduação), Pontifícia Universidade Católica do Rio Grande do Sul, Porto Alegre, Brasil.

Borges, A. M. B., \& Carlotto, M. S (2004). Síndrome de Burnout e fatores de estresse em estudantes de um curso técnico de enfermagem. Aletheia, (19),45-56. Recuperado de http://pepsic.bvsalud.org/pdf/aletheia/n19/n19a05. pdf 
Bosi, M. L. M., \& Elias, T. F. (2000). Um novo caminho: perfil e trajetórias de alunos de Psicologia ingressos como portadores de diploma. Estudos de Psicologia, 17(2), 31-40. doi: 10.1590/S0103-166X2000000200003

Campos, J. A. D. B., Carlotto, M. S., \& Marôco, J. (2013). Copenhagem Burnout Inventory - Student version: adaptation and transcultural validation for Portugal and Brazil. Psicologia: Reflexão e Crítica, 26(1), 87-89. doi: 10.1590/S0102-79722013000100010

Carlotto, M. S., \& Câmara, S. G. (2006). Características psicométricas do Maslach Burnout Inventory - Student Survey (MBI-SS) em estudantes universitários brasileiros. PsicoUSF, 11(2), 167-163. Recuperado de http://www. scielo.br/pdf/pusf/v11n2/v11n2a05

Carlotto, M. S., Câmara, S. G., Otto. F., \& Kauffmann, P. (2009). Síndrome de Burnout e coping em estudantes de Psicologia. Boletim de Psicologia, 59(131), 167-178. Recuperado de http://pepsic.bvsalud.org/pdf/bolpsi/ v59n131/v59n131a04.pdf

Carlotto, M. S., Nakamura, A. P., \& Câmara, S. G. (2006). Síndrome de Burnout em estudantes universitários da área da saúde. Psico, 37(1), 57-62.

Ferraz, H. F., Cardona, S., \& Monte, P. G. (2009). Psychological exhaustion and disorders of health in psychology students. Psicologia em Estudo, 14(2), 349353. Recuperado de http://www.scielo.br/pdf/pe/v14n2/ v14n2a15.pdf

Ferreira, N. N. (2012). Síndrome do esgotamento profissional e fatores associados em técnicos de Enfermagem de um hospital público do Estado de São Paulo (Tese Doutorado), Universidade Estadual de Campinas, Campinas, Brasil.

Fogaça, M. C., Hamasaki, E. I. M., Barbieri, C. A. P., Borsetti, J., Martins, R. Z., Silva, I. G., \& Ribeiro, L. P. (2012). Burnout em estudantes de psicologia: diferenças entre estudantes iniciantes e concluintes. Aletheia, (38-39), 124-131. Recuperado de http://pepsic.bvsalud.org/pdf/ aletheia/n38-39/n38-39a10.pdf

França, F. M., \& Ferrari, R. (2012). Síndrome de Burnout e os aspectos sócio-demográficos em profissionais de enfermagem. Acta Paulista Enfermagem, 25(5), 743-748. Recuperado de http://www2.unifesp.br/acta/pdf/v25/ n5/v25n5a15.pdf

Igue, E. A., Bariani, I. C. D., \& Milanesi, P. V. B. (2008). Vivência acadêmica e expectativa de universitários ingressantes e concluintes. Psico-USF, 13(2), 155-164. Recuperado de http://pepsic.bvsalud.org/pdf/psicousf/ v13n2/v13n2a03.pdf

Jacques, M. G. C., Borges, L. O., \& Cassiolato, R. H. H. (2010). Saúde/doença no trabalho do psicólogo: a síndrome de Burnout. In A. V. B. Bastos, S. M. G. Gondim (Orgs.), O trabalho do psicólogo no Brasil. (pp. 358-434). Porto Alegre: ARTMED.

Kovaleski, D. F., \& Bressan, A. (2012). A Síndrome de Burnout em profissionais de saúde. Saúde \& Transformação Social, 3(3), 107-113. Recuperado de http://gestaoesaude.unb. br/index.php/gestaoesaude/article/view/185/pdf_1
Lorenz, V. R., Benatti, M. C. C., \& Sabino. M. O. (2010). Burnout e estresse em enfermeiros de um hospital universitário de alta complexidade. Revista Latino Americana de Enfermagem, 18(6), 1084-91. Recuperado de http://www.scielo.br/pdf/rlae/v18n6/pt_07

Maia, D. A. C, Maciel, R. H. M. O., Vasconcelos, J. A., Vasconcelos, L. A., \& Filho, J. O. V. (2012). Síndrome de Burnout em estudantes de medicina: relação com a prática de atividade física. Cadernos ESP, Ceará, 6(2), 50-59.

Maroco, J., \& Tecedeiro, M. (2009). Inventário de Burnout de Maslach para estudantes portugueses. Psicologia, Saúde \& Doenças, 10(2), 227-235. Recuperado de http:// repositorio.ispa.pt/handle/10400.12/1090

Matos, A. A., \& Júnior, M. D. (2008). A incorporação do gênero no estudo da Síndrome de Burnout. Unimontes Cientifica, 10(1/2), 25-33. Recuperado de http://www. ruc.unimontes.br/index.php/unicientifica/article/ view/232/224

Meira, C. H. M. G., \& Nunes, M. L. T. (2005). Psicologia clínica, psicoterapia e o estudante de psicologia. Paidéia, 15(32), 339-343. doi: 10.1590/S0103-863X2005000300003

Ministério de Estado da Saúde - MES (1999). Portaria $\mathrm{n}^{\circ}$ 1339/99. Listas de Doenças Relacionas ao Trabalho. 18 de novembro de 1999.

Osternack, J. V., Gonçalves, L. M., \& Amorim, C. (2007). Avaliação da síndrome de Burnout em estudantes do Curso técnico em enfermagem de uma instituição Privada na região de Curitiba-PR. Apresentação oral no congresso da PUCPR, Curitiba, PR.

Papalia, D. E., Olds, S. W., \& Feldman, R. D. (2006). Desenvolvimento Humano. Porto Alegre: Artmed.

Pereira, A. M. T. B. (2002). Burnout, Por quê? In Pereira, A. M. T. B. (Org.), Burnout: quando o trabalho ameaça o bem-estar do trabalhador $1^{\mathrm{a}}$ ed., (pp. 13-20). São Paulo: Casa do Psicólogo.

Rudnicki, T., \& Carlotto, M. S. (2007). Formação de estudantes da area da saúde: reflexões sobre a prática de estágio. Revista da SBPH, 10(1), 97-110. Recuperado de http://pepsic.bvsalud.org/pdf/rsbph/v10n1/v10n1a08. pdf

Schaufeli, W. B., Leiter, M. P., Maslach, C., \& Jackson, S. E. (1996). MBI-General Survey. Palo Alto.

Selig, L., Geluda, K., Junqueira, T., Brito, R., \& Trajman, A. (2012). A tuberculose no cotidiano médico e o efeito bumerangue do abandono. Ciência \& Saúde Coletiva, 17(1), 113-122. Recuperado de http://www. scielo.br/pdf/csc/v17n1/a14v17n1

Tarnowski, M., \& Carlotto, M. S. (2007). Síndrome de Burnout em estudantes de psicologia. Temas em Psicologia, 15(2), 173-180. Recuperado de http://pepsic.bvsalud. org/pdf/tp/v15n2/04.pdf

Telles, H., \& Pimenta, A. M. C. (2009). Síndrome de Burnout em Agentes comunitários de saúde e estratégias de enfrentamento. Saúde e Sociedade, 18(3), 467-478. doi: 10.1590/S0104-12902009000300011 
Tomaschewski-Barlem, J. G. T., Lunardi, V.L., Lunardi, G. L., Barlem, E. L. D., Silveira, R. S., \& Vidal, D. A. S. (2014). Síndrome de Burnout entre estudantes de graduação em enfermagem de uma universidade pública. Revista Latino-Americana de Enfermagem, 22(6), 934-941. doi: 10.1590/0104-1169.3254.2498
Tomaschewski-Barlem, J. G., Lunardi, V. L., Ramos, A. M., Silveira, R. S., Barlem, E. L. D., \& Ernandes, C. M., (2013). Manifestações da síndrome de Burnout entre estudantes de graduação em enfermagem. Texto \& Contexto - Enfermagem, 22(3), 754-762. 